Elsevier required licence: ( 2019

This manuscript version is made available under the CC-BY-NC-ND 4.0 license http://creativecommons.org/licenses/by-nc-nd/4.0/

The definitive publisher version is available online at https://doi.org/10.1016/j.desal.2018.02.002 


\title{
Hybrid Desalination Processes for Beneficial Use of Reverse Osmosis Brine: Current Status and Future Prospects
}

\author{
Sangho Lee ${ }^{1}$, Juneseok Choi ${ }^{2}$, Yong-Gyun Park ${ }^{3}$, Ho Kyong Shon ${ }^{4}$, Chang Hoon Ahn ${ }^{5,6}$, Seung-Hyun Kim ${ }^{5,6 *}$
}

${ }^{1}$ School of Civil and Environmental Engineering, Kookmin University, 77 Jeongneung-ro, Jung-gu, Seoul, Republic of Korea

${ }^{2}$ Korea Institute of Construction Technology, Goyang-si, Gyeonggi-do, Republic of Korea

${ }^{3}$ Environmental Process Engineering Team, GS Engineering \& Construction (GS E\&C), Seoul, Republic of Korea

${ }^{4}$ School of Civil and Environmental Engineering, University of Technology Sydney, Australia

${ }^{5}$ GMVP Research Center, Seoul, Republic of Korea

${ }^{6}$ Department of Civil Engineering, Kyungnam University, 7 Kyungnamdaehak-ro, Masanhappo-gu, Changwon-si,

Gyeongsangnam-do, Republic of Korea

*Corresponding author: email: shkim@kyungnam.ac.kr

\begin{abstract}
As water shortage has increasingly become a serious global problem, desalination using seawater reverse osmosis (SWRO) is considered as a sustainable source of potable water sources. However, a major issue on the SWRO desalination plant is the generation of brine that has potential adverse impact due to its high salt concentration. Accordingly, it is necessary to develop technologies that allows environmentally friendly and economically viable management of SWRO brines.

This paper gives an overview of recent research works and technologies to treat SWRO brines for its beneficial use. The treatment processes have been classified into two different groups according to their final purpose: 1) technologies for producing fresh water and 2) technologies for recovering energy. Topics in this paper includes membrane distillation (MD), forward osmosis (FO), pressure-retarded osmosis (PRO), reverse electrodialysis (RED) as emerging tools for beneficial use of SWRO brine. In addition, a new approach to simultaneously recover water and energy from SWRO brine is introduced as a case study to provide insight into improving the sustainability of seawater desalination.
\end{abstract}

Keywords: desalination, reverse osmosis, brine, water, energy, pressure retarded osmosis, membrane distillation 


\section{Introduction}

One of the most inevitable resources for human being is fresh water. However, the scarcity of fresh water has becoming a serious threat, which results from rapid increase in water demand for urban, economic, and industrial development [1]. In addition, global climate change by the emission of greenhouse gas alters rainfall patters, leading to an extreme drought in many regions all over the world $[2,3]$. The is one of the motivations for the implementation of seawater desalination, which allows sustainable supply of fresh water from seawater [4]. Accordingly, the global capacity of desalination has increased since 1970s and reached over 120,000,000 $\mathrm{m}^{3} /$ day in 2016 [5-8].

While desalination has been widely applied, one of the main issues associated with seawater desalination is its high energy requirement. Thermal desalination such as multi-stage flash (MSF) and multi-effect distillation (MED) uses a lot of thermal energy and electricity. Membrane desalination using seawater reverse osmosis (SWRO) uses less energy than thermal desalination but its energy consumption is still substantial. Currently, the energy consumption by SWRO process in large-scale membrane desalination plants ranges from 2.0 $\mathrm{kWh} / \mathrm{m}^{3}$ to $3.5 \mathrm{kWh} / \mathrm{m}^{3}$ and their plantwise energy consumption ranges from $3.5 \mathrm{kWh} / \mathrm{m}^{3}$ to $5.0 \mathrm{kWh} / \mathrm{m}^{3}$ [9]. This is still significantly higher than the energy requirements for utilizing surface water or groundwater and reusing wastewater. Although many studies have been carried out to utilize renewable energy sources, the energy requirement for SWRO should be lowered as much as possible [10].

Another issue to be addressed is the handling of SWRO brine, which has a higher salt concentration than seawater [11]. The amount and salt concentration of brine depend on the recovery of the desalination process [12]. At $40 \%$ recovery, the amount of the brine is 1.5 times larger than that of the desalinated water and the salt concentration is approximately 1.66 times higher than that of the seawater. In most cases, the brine is directly discharged into sea without any treatment. However, it is anticipated that the brine discharge results in adverse impact on the ecosystem in the sea $[12,13]$. There are other options such as deep well injection, disposal to land, and evaporation ponds [13]. However, they are generally considered for inland desalination and also limited due to technological and economic reasons.

Due to its higher salt concentration, it is challenging to deal with SWRO brine. There are two possible ways of advanced brine management: volume reduction and concentration reduction (Figure 1). The first approach 
is to further concentrate brine to decrease its volume. Mechanical or thermal evaporation, forward osmosis, and membrane distillation have been considered for this purpose. The second approach is to remove salt from the brine to reduce its environmental impact after its discharge. In addition, the salt concentration in the brine can be reduced by utilizing osmotic power, which also allows the recovery of energy. Pressure retarded osmosis and reverse electrodialysis have been investigated for this purpose. In fact, it is necessary to change the paradigm that SWRO brine is not a waste but a source of water and energy. This may be realized by implementing the recovery of additional water and energy from SWRO brine.

This paper reviews the state-of-art approaches for brine management for seawater desalination. Two types of advanced brine management techniques are presented, including 1) technologies for producing fresh water and 2) technologies for recovering energy. Topics in this paper includes membrane distillation (MD), forward osmosis (FO), pressure-retarded osmosis (PRO), reverse electrodialysis (RED) as emerging tools for beneficial use of SWRO brine. Prospect of simultaneous recovery of water and energy from SWRO brine is also discussed.

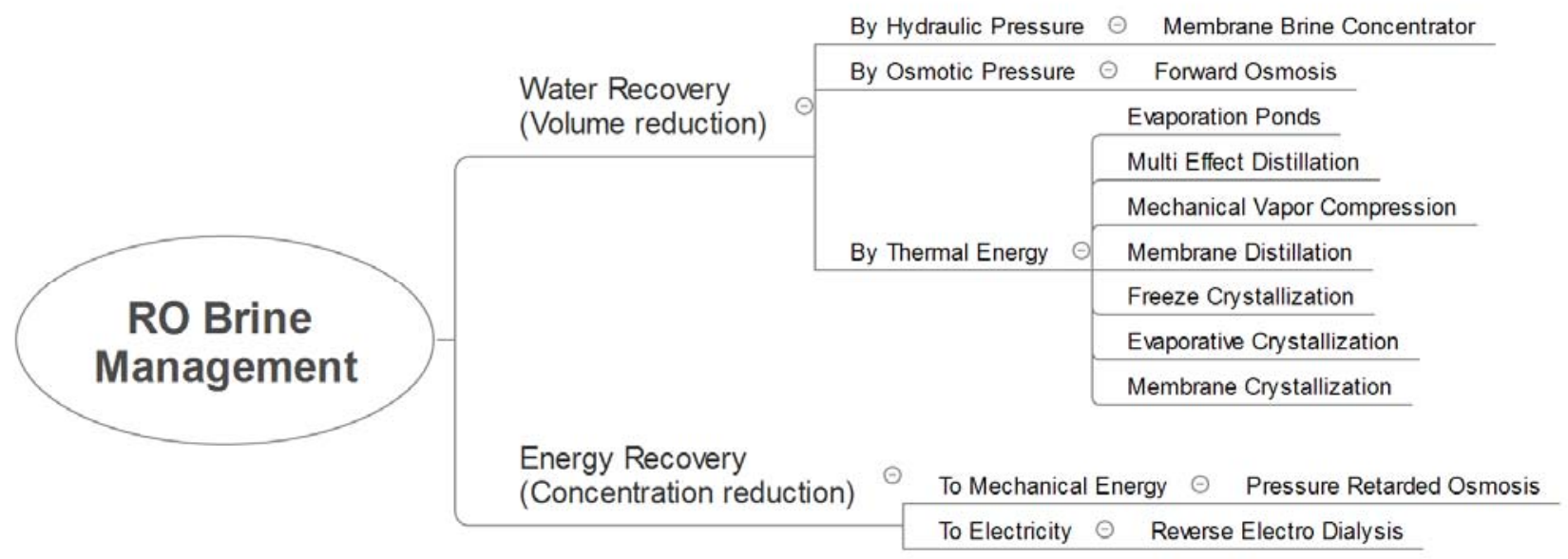

Figure 1. Technologies for SWRO brine management by water recovery and energy recovery

\section{Technologies for producing fresh water from SWRO brine}

\subsection{Technological requirements}

Seawater with the $\mathrm{NaCl}$ concentration ranging from $3.0 \%$ to $4.5 \%$ (or $0.51-0.765 \mathrm{~mole} / \mathrm{L}$ ) results in the osmotic pressure between 25 and 37 bar at $25{ }^{\circ} \mathrm{C}$. Assuming that the recovery of product water in SWRO 
processes ranges from $30 \%$ to $50 \%$, the osmotic pressure of the brine is between 35.7 bar and 74.2 bar. If the salt concentration of the seawater is higher, the recovery in SWRO processes becomes lower, leading the maximum osmotic pressure of the brine less than 75 bar in most cases.

Therefore, technologies for producing fresh water from SWRO brine should be able to overcome such a high osmotic pressure. RO is not suitable for this purpose since a very high pressure is required to further concentrate the SWRO brine. Instead, thermal processes are generally considered. Although the vapor pressure is affected by the salt concentration of the SWRO brine, which is called the boiling point elevation (BPE), it is less sensitive to the salt concentration than the osmotic pressure. Accordingly, it is still possible to treat the SWRO brine using such thermal processes.

Another approach to overcome the high osmotic pressure of the SWRO brine is to apply higher pressure in osmotic processes. This is not possible nor practical in RO processes due to the limitations of current mechanical equipments and pumps. But it can be done in forward osmosis (FO) processes that use osmotic pressure as their driving force. For example, the ammonium-carbon dioxide draw solution of 6 mole/L results in approximately 250 bar, which is enough to extract fresh water from the SWRO brine. Of course, the recovery of draw solutes is required after the FO treatment and it is generally based on thermal separation processes.

\subsection{Membrane brine concentrator}

Although conventional RO is not appropriate to treat the SWRO brine from seawater desalination plants, it is still possible to apply a specially designed RO system called membrane brine concentrator. There is a proprietary process, which is capable of treating high TDS feed water ranging from $70,000 \mathrm{mg} / \mathrm{L}$ to 165,000 $\mathrm{mg} / \mathrm{L}$ [14]. Since it uses electrical power, it is possible to avoid the use of thermal energy and allows simplicity of operation. However, membrane brine concentrators are generally considered for industrial wastewater treatment rather than seawater desalination. The energy consumption was reported to range from $10 \mathrm{kWh} / \mathrm{m}^{3}$ to $15 \mathrm{kWh} / \mathrm{m}^{3}$.

\subsection{Forward osmosis}

FO has become an evolving membrane technologies not only for seawater desalination but also 
wastewater treatment and reuse due to expanded interests in its low energy and low fouling potential [15]. Accordingly, there have been studies on the use of FO for the SWRO brine treatment [15-20]. However, some of these works focused on the treatment of SWRO brine from brackish water desalination or wastewater reclamation. This is attributed to the requirement of high osmotic pressure for FO processes for SWRO brine treatment. Moreover, the recovery of draw solutes after the FO treatment of the SWRO brine is challenging [21]. In fact, the application of FO processes for high salinity feed water has been done not for SWRO brine treatment but for the treatment of shale gas produced water [22, 23] or zero liquid discharge system [24].

Recently, osmotically assisted reverse osmosis (OARO), which combines RO with FO, was suggested for high salinity brine treatment [25]. According to this study, the OARO process was found to have a $35-50 \%$ water recovery with an energy consumption of $6-19 \mathrm{kWh}$ per $\mathrm{m}^{3}$ of product water for a feed solution of 100 $140 \mathrm{~g} / \mathrm{L} \mathrm{NaCl}$.

\subsection{Thermal/mechanical evaporation}

Thermal process such as evaporation is a conventional technique to treat SWRO brine [26]. Evaporation ponds are natural processes that lead the evaporation of water from SWRO brine by the sun [27,28]. They are successfully used in regions with dry weather, high evaporation rates, and availability of land at low cost [26, 29]. Wind can also help to evaporate water from SWRO brine and this systems is called a wind aided intensified evaporator [30]. However, due to its high footprint, it is not applicable to areas with high land costs. Accordingly, the application of evaporation ponds are limited to be implemented in small scale inland desalination systems.

Combination of RO with thermal processes to reduce brine is not a novel concept [31]. Traditional thermal desalination such as multi-effect distillation (MED) and mechanical vapor compression (MVC) can be applied to treat SWRO brine. In theory, the use of MED can significantly reduce the SWRO brine. However, scale formation on heat exchanger surfaces due to the precipitation of silica and calcium salts prevents to achieve it. MVC is also a distillation process but does not require an excessive use of thermal energy. Instead, it uses electrical energy to mechanically compress vapor to increase temperature required for evaporation. Nevertheless, MVC is preferentially considered for ZLD in industrial wastewater treatment. In addition to MED and MVC, thermal brine concentrator is another technique for SWRO brine treatment [32]. 


\subsection{Membrane distillation}

Recently, membrane distillation (MD) has drawn attention as a promising technique to treat the SWRO brine [33-37]. MD is a thermal separation process and thus less sensitive to salt concentration than RO or FO [38-40]. Moreover, MD can be operated under lower temperature than MED or MVC, allowing the use of low grade heat such as solar thermal energy and waste heat from power plants or other industrial plants $[39,41$, 42]. This makes MD more attractive than other thermal techniques for SWRO brine treatment [40, 43, 44]. The performance of different configurations including direct contact MD [35, 36], vacuum MD [33], and submerged MD [34] has been evaluated for the treatment of SWRO brine.

Nevertheless, fouling is a critical problem in treating the SWRO brine using MD [34, 36]. Due to high concentrations of salts, scale formation easily occurs together with other fouling phenomena. Previous results showed that the predominant foulants are inorganic, including calcium sulfate, halite $(\mathrm{NaCl})$, biopolymers, and humic like substances [45]. As the feed temperature increased, membrane wetting became more significant, resulting in reduced flux and salt rejection [46].

\subsection{Crystallization}

Although thermal separation techniques are useful to reduce the volume of the brine, they have limitations given by precipitation of dissolved salts. Accordingly, it is necessary to apply crystallization for further treatment of SWRO brine. There are two types of crystallization including freeze crystallization and evaporative crystallization [28]. In the freeze crystallization, the SWRO brine is cooled until its temperature becomes the eutectic temperature, which is essential for crystal formation [47]. In the evaporative crystallization, additional thermal energy is added until the crystals are formed. In this case, vapor from the compressor increase the brine temperature and the water is allowed to evaporate, leading to crystallization of salts from the concentrated solution [48].

In addition to conventional crystallization techniques, membrane crystallization is increasingly gaining interest as a brine treatment option [49-53]. Membrane crystallization allowed the operation at moderate temperature $\left(40-50{ }^{\circ} \mathrm{C}\right)$ while conventional evaporation for $\mathrm{NaCl}$ crystallization is operated at temperature over $70{ }^{\circ} \mathrm{C}$ [51]. However, fouling is also a critical issue in membrane crystallization of the SWRO brine [52]. 
One of the approaches for this problem is the control of bulk crystallization and surface crystallization in membrane crystallization, which has potential to induce crystallization and de-supersaturation without causing membrane fouling [54].

\section{Technologies for recovering energy from SWRO brine}

\subsection{Technological requirements}

Salinity gradient energy (SGE) is an energy source relying on the energy that dissipates when two solutions with different salinities mix [55]. As mentioned earlier, SWRO brine has high salt concentration ranging from $4.3 \%$ to $9.0 \%$ and high osmotic pressure ranging from 35.7 bar and 74.2 bar. This implies that SWRO brine has potential as a source of salinity gradient energy by mixing it with fresh water. In general, impaired water sources such as reclaimed wastewater are used as the fresh water for recovering salinity gradient energy [56]. The theoretical extractable work was calculated as $2.75 \mathrm{kWh} / \mathrm{m}^{3}$ of draw solution used, as opposed to 0.75 $\mathrm{kWh} / \mathrm{m}^{3}$ in seawater - river water systems [57]. In practical situation, the amount of energy to be obtained is less than this maximum value.

Technologies for recovering energy from SWRO brine need to have capabilities to convert the mixing energy to mechanical energy or electricity. For this purpose, there are two approaches including pressure retarded osmosis (PRO) and reverse electrodialysis (RED). In PRO processes, water transports from the fresh (or impaired) water side to the SWRO brine though an osmotic membrane $[56,58,59]$. At the same time, a certain degree of pressure is applied and the mechanical energy is generated from the chemical potential. In RED processes, ion exchange membranes are used to build up electrical potential that acts as a driving force to generate electricity $[60]$.

\subsection{Pressure retarded osmosis (PRO)}

Before PRO was considered for energy recovery from SWRO brine, it was applied to generate electricity using river water and seawater. The Norwegian company of Statkraft began the first prototype PRO installation in 2009. However, the Statkraft announced their decision to terminate the PRO project in 2013, saying that it is not possible to justify the osmotic power in Europe. In fact, the power density and the net specific energy from the PRO system using river water and sweater are not sufficiently high. According to a 
recent study, the overall net specific energy that may be recovered by such a PRO system is approximately $0.12 \mathrm{kWh} / \mathrm{m}^{3}$ [57]. Moreover, it was estimated that the power density should be in the range of $4 \sim 6 \mathrm{~W} / \mathrm{m}^{2}$ to make PRO economically feasible in Norwegian energy market but the actual power density from the pilot study was much lower.

Instead, the use of SWRO brine for PRO has gained increasing interest. Based on a theoretical analysis, it was reported that the SWRO-PRO hybrid system was found to be energy efficient solution [61]. Another modeling study reports that the specific energy consumptions for SWRO with PX and SWRO-PRO with PX are 1.79 and $1.08 \mathrm{kWh} / \mathrm{m}^{3}$ of desalinated water for a $25 \%$ recovery SWRO plant and 2.27 and $1.14 \mathrm{kWh} / \mathrm{m}^{3}$ of desalinated water for a 50\% recovery, respectively [62]. These results suggest that PRO using RO-brine can be energetically justified.

In 2010, a Japanese R\&D project on seawater desalination called "Mega-ton" project started to perform a SWRO-PRO pilot-scale study. Mega-ton project implemented a PRO process using the SWRO brine as the draw solution, and the treated waste water as the feed solution [59]. The Toyobo company developed hollow fiber PRO membrane modules with a module power density of $12 \mathrm{~W} / \mathrm{m}^{2}$ at around 30 bar applied hydraulic pressure on the draw solution side $[59,63]$. A PRO pilot plant of $460 \mathrm{~m}^{3} /$ day brine flow rate capacity was constructed and operated in Fukuoka, Japan [56].

Membrane fouling is also a serious problem that reduces the efficiency of PRO systems. Without proper pretreatment, the power density and the specific energy of PRO may significantly decrease. On the other hand, use of energy-intensive pretreatment such as ultrafiltration results in a reduction in net specific energy by PRO. Accordingly, the optimization of pretreatment for PRO is a key to successful implementation of PRO [64]. Nevertheless, little information is available on the pretreatment guidelines for PRO membranes [65]. In a recent study, turbidity, SDI and MFI were compared as a way to predict the maximum power density of PRO system [66]. Results showed that turbidity was too sensitive, and SDI was insensitive in terms of prediction of power density. On the other hand, MFI was found to be appropriate for reliable prediction of power density in a PRO system.

\subsection{Reverse electrodialysis (RED)}

RED is another option for recovering energy from SWRO brine. Unlike PRO, only ions pass through ion 
exchange membranes, leading to direct generation of electricity [67]. Accordingly, RED was initially considered for electricity production as a renewable energy source. On the other hand, relatively few works have been done to combine SWRO with RED to recovery energy from SWRO brine.

Compared with PRO, the power density of RED is generally lower [68]. According to a theoretical estimation, the maximum net power density for RED with the current technology was calculated at $2.7 \mathrm{~W} / \mathrm{m}^{2}$ [69]. However, by changing the cell design, the membrane resistance, and the cell length, it was expected that calculated net power density can be improved up to $20 \mathrm{~W} / \mathrm{m}^{2}$ or more [67].

\section{Simultaneous recovery of water and energy from SWRO brine: Global MVP project}

\subsection{Overview}

As mentioned earlier, SWRO brine can be used to produce more water or generate energy. If it is used for both purposes at the same time, synergic effects are expected. First of all, the SWRO brine after the water recovery by FO, MVC or MD, its salt concentration increases. So it still has a similar impact on the marine environment if discharged. If this concentrated RO brain is used as the feed water (draw solution) to PRO or RED, it is diluted and thus has a low environmental impact. Moreover, the power density of the PRO increases due to the use of the concentrated SWRO brine. This is the reason that a simultaneous recovery of water and energy from SWRO brine should be implemented.

With this motivation, a Korean R\&D project on SWRO brine treatment called the Global MVP, or GMVP project was launched in 2013. The GMVP project focused on scaling-up of MD, PRO, and resource recovery technologies and demonstration of hybrid desalination systems for the recovery of water, energy, and resources from SWRO brine. There are three possible hybrid systems, including 1) RO-MD; 2) RO-PRO; and 3) RO-MD-PRO. The RO-MD hybrid system was intended to reduce the volume of SWRO brine by 30 percent. The RO-PRO hybrid system aimed at the power density of $7.5 \mathrm{~W} / \mathrm{m}^{2}$ in pilot-scales. The RO-MDPRO hybrid system used a wastewater treatment plant as a feed solution and a MD brine as a draw solution. In addition, technologies to recover lithium or other valuable metal ions from RO or MD brines, and manufacture construction materials such as paving blocks are included in the hybrid systems. Schematics of these hybrid systems are illustrated in Figure 2. 


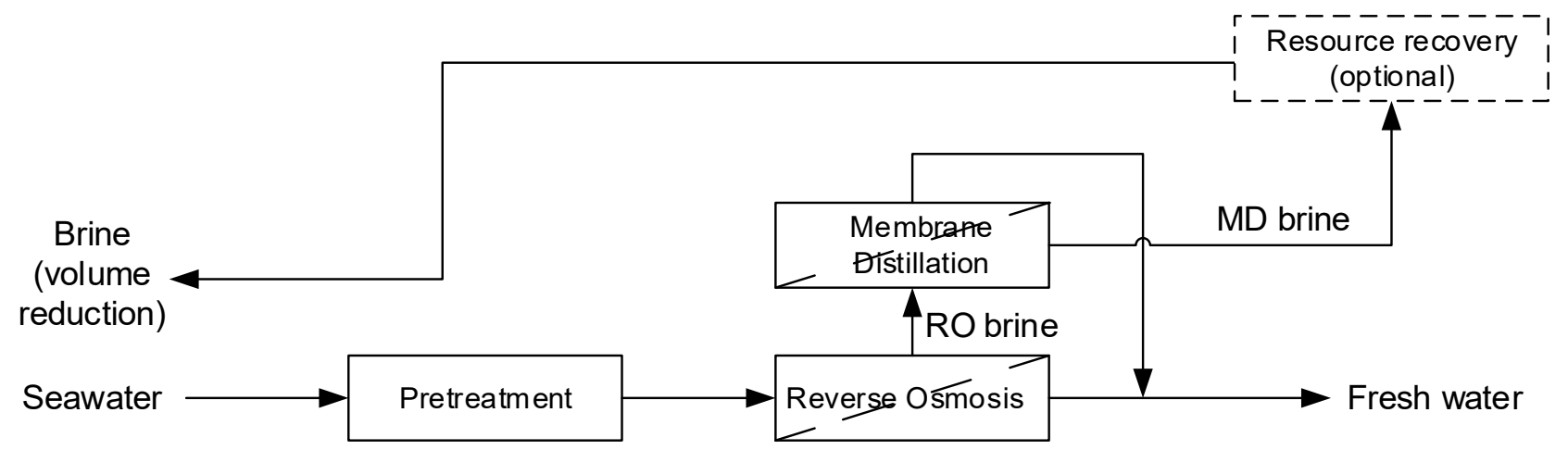

(a)

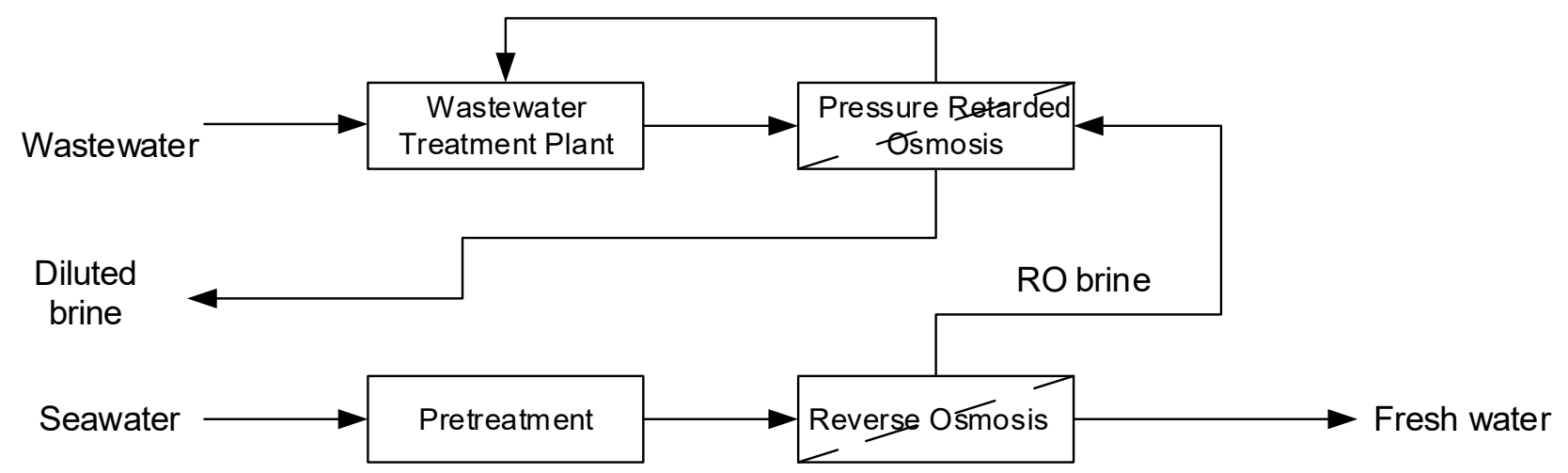

(b)

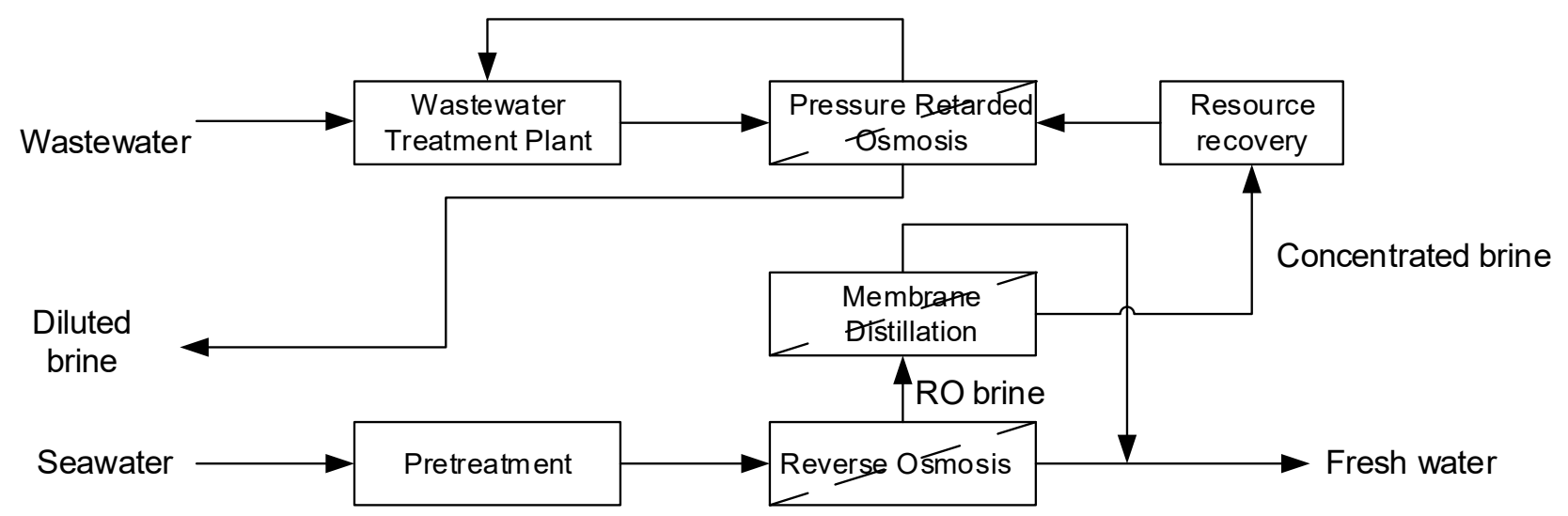

(c)

Figure 2. Schematics of Global MVP process for water and energy recovery from SWRO brine. (a) Water recovery using MD (b) Energy recovery using PRO (c) Simultaneous recovery of water and energy using 
$\mathrm{MD} / \mathrm{PRO}$

\subsection{MD technologies for water recovery from SWRO brine}

Previous works on pilot-scale MD were carried out using flat sheet or spiral wound modules [70]. Although they have several advantages, the module configurations are quite complex, leading to an issue during the scale-up to a large-scale MD systems. Accordingly, hollow fiber MD membranes were developed and used to fabricate modules with the membrane area ranging from $7.6 \mathrm{~m}^{2}$ to $20 \mathrm{~m}^{2}$ in the GMVP project. The hollow fiber MD modules was tested in direct contact MD and vacuum MD configurations [71] although it is also possible to adopt an air gap MD configuration in laboratory scale systems [72]. Compared with vacuum MD, direct contact MD showed a lower performance ratio (PR) due to conductive heat loss and other losses. Accordingly, vacuum MD was selected as the configuration for pilot-scale MD systems. Moreover, thermal vapor compression (TVC) was applied to recover heat from the vapor to increase PR (Figure 3).

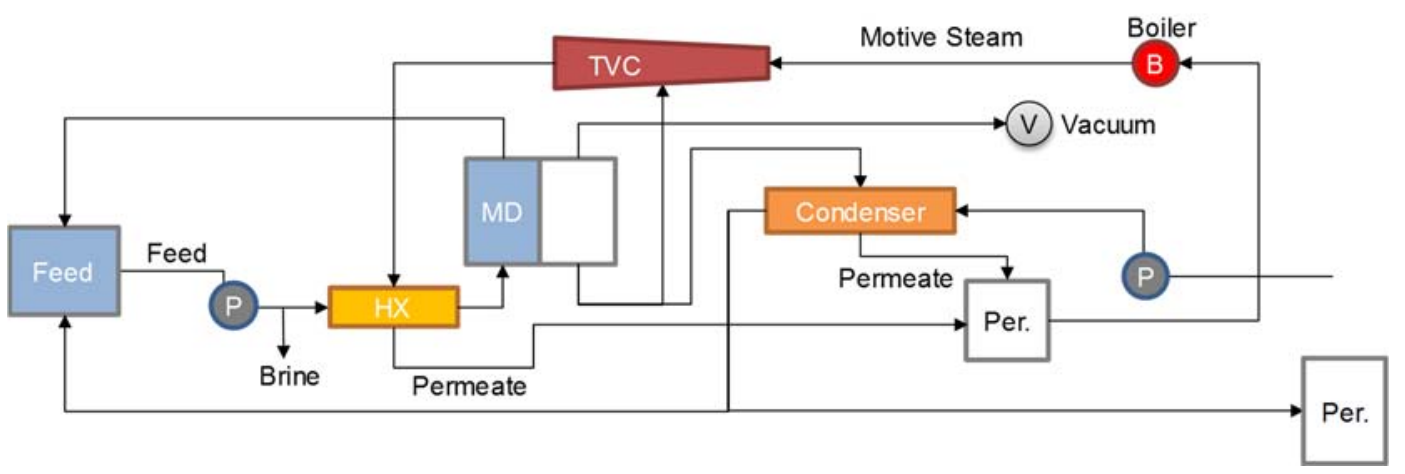

Figure 3. Schematics of MD-TVC system

Membrane fouling and wetting are major problems in MD application. Experiments were carried out to show that inorganic fouling dominates in MD for SWRO brine but minor organic fouling accelerates the fouling phenomena. Interestingly, organic constituent migrated to the permeate side of the membrane, suggesting that the possible passage of low molecular organic matters through the MD membranes. In addition, several attempts were done to control the wetting of MD membranes, including the dewetting of wetted pores by applying warm air flow [73]. 
The performance of a vacuum MD system was examined in a pilot plant of $10 \mathrm{~m}^{3} /$ day [74]. Factors affecting MD flux were examined, including feed temperature, feed flow rate, and applied vacuum. Results showed that the MD flux was almost linearly proportional to feed temperature and flow rate. Moreover, the flux was also sensitive to the applied vacuum. Based on this study, a larger MD pilot plant with the design capacity of $400 \mathrm{~m}^{3} /$ day was designed for SWRO brine treatment.

\subsection{PRO technologies for energy recovery from SWRO brine}

In the GMVP project, 8 inch spiral wound PRO elements were used, which had $18 \mathrm{~m}^{2}$ in total membrane area. The membranes had a polyamide active layer and their physical characteristics were similar to those reported previously [75]. Although the initial performance was not high, the PRO elements had continuously improved to have higher power density and recovery. Three versions of PRO membrane modules (CSM-PRO1, CSM-PRO-2, CSM-PRO-3) have been developed and compared with the applied hydraulic pressure of 20 bar [75]. The first version of the PRO membrane module showed $2.3 \mathrm{~L} / \mathrm{m}^{2}-\mathrm{hr}$ of permeate flux and $9.2 \% \mathrm{FS}$ recovery. These performance values were improved greatly with the second and third versions: $300 \%$ and $574 \%$ in flux, and $224 \%$ and $440 \%$ in recovery, respectively. The single-element module of the latest version, CMS-PRO-3, could achieve $13.2 \mathrm{~L} / \mathrm{m}^{2}$-hr flux and $40.2 \%$ recovery.

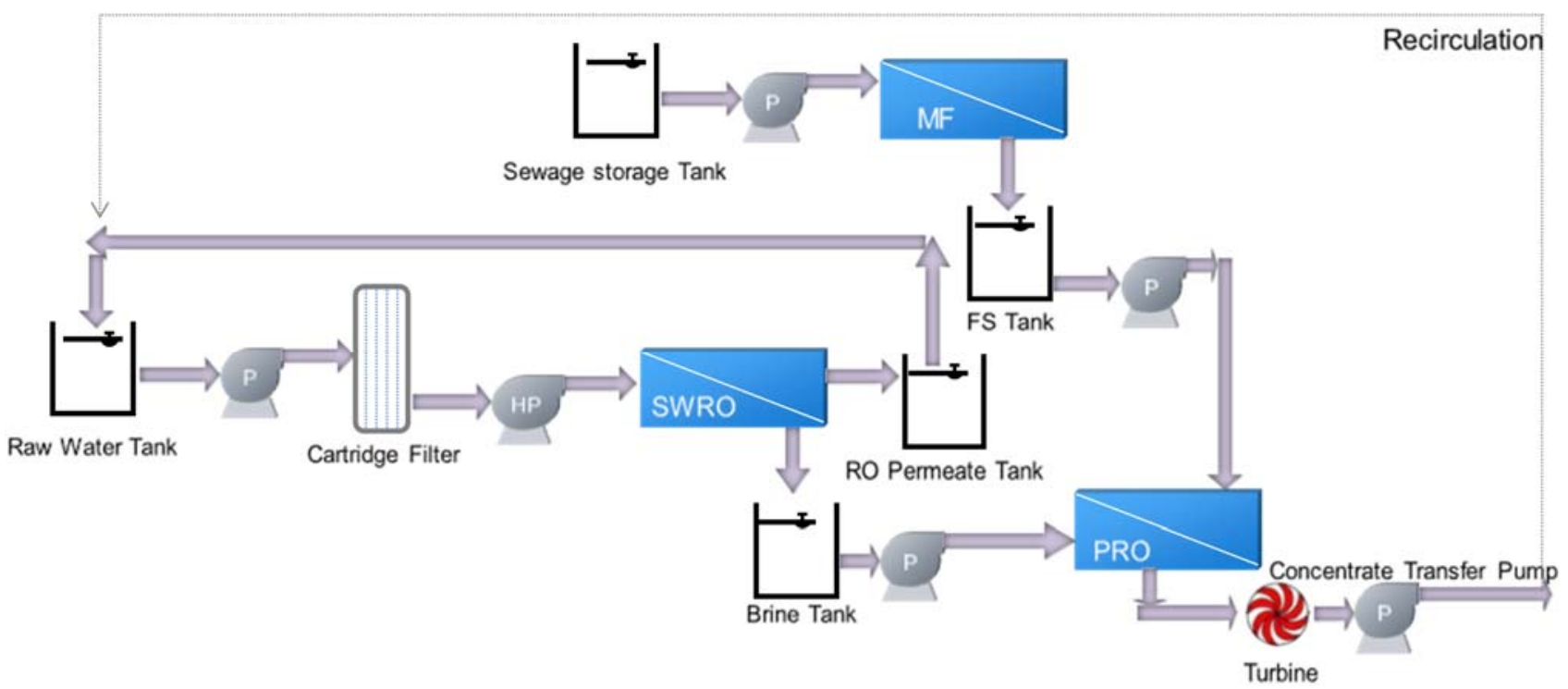

Figure 4. Overview of SWRO-PRO pilot plant ( $20 \mathrm{~m}^{3} /$ day $)$ 
Two SWRO-PRO pilot plants were constructed and operated (Figure 4). The first pilot plant had the capacity of $20 \mathrm{~m}^{3} /$ day and the second pilot plant had the capacity of $240 \mathrm{~m}^{3} /$ day. The effect of feed water types and pretreatment on PRO performance were investigated in the first pilot plant [76]. Secondary effluent and tertiary effluent were compared as the feed solution to PRO but the difference was not significant. In some cases, the fouling rate was higher for the tertiary effluent than the secondary effluent due to the use of coagulant polymer that has adverse impact on the PRO membrane fouling. On the other hand, the use of ultrafiltration for the polishing of the feed solution was effective to retard PRO fouling. Similar results were also obtained in laboratory-scale experiments [66].

In the pilot plant, the performance of the PRO module was investigated experimentally, and the results were compared with simulations. The maximum power density of the PRO membrane module was $14 \mathrm{~W} / \mathrm{m}^{2}$ at 28 bar using a solution with $70,000 \mathrm{mg} / \mathrm{L}$ of sodium chloride $(\mathrm{NaCl})$. In the pilot plant, the overall power density was lower but still be in the range of $6 \mathrm{~W} / \mathrm{m}^{2}$ to $8 \mathrm{~W} / \mathrm{m}^{2}$ using the $4^{\text {th }}$ generation PRO element. The flux and recovery were $16.4 \mathrm{~L} / \mathrm{m} 2-\mathrm{hr}$ and $49.3 \%$, respectively.

\subsection{Economic analysis}

The performance and economics of SWRO, SWRO-MD, SWRO-PRO, and SWRO-MD-PRO were compared using theoretical models [77]. Results showed that the hybrid systems can outperform an RO standalone system in terms of its ability to reduce water cost and alleviate the disposal and environmental problems of waste brine. The electricity cost plays a dominant role in determining economic feasibility of hybrid plants. If the electricity cost exceeds $0.2 \$ / \mathrm{kWh}$, the water costs of hybrid desalination systems such as SWRO-MD, SWRO-PRO, and SWRO-MD-PRO are lower than that of SWRO single process. The steam cost for MD heating source plays a dominant role in determining economic feasibility of RO-MD and RO-MD-PRO hybrid systems. The membrane cost and interest rate are also crucial factors affecting the economic feasibility of hybrid systems. 


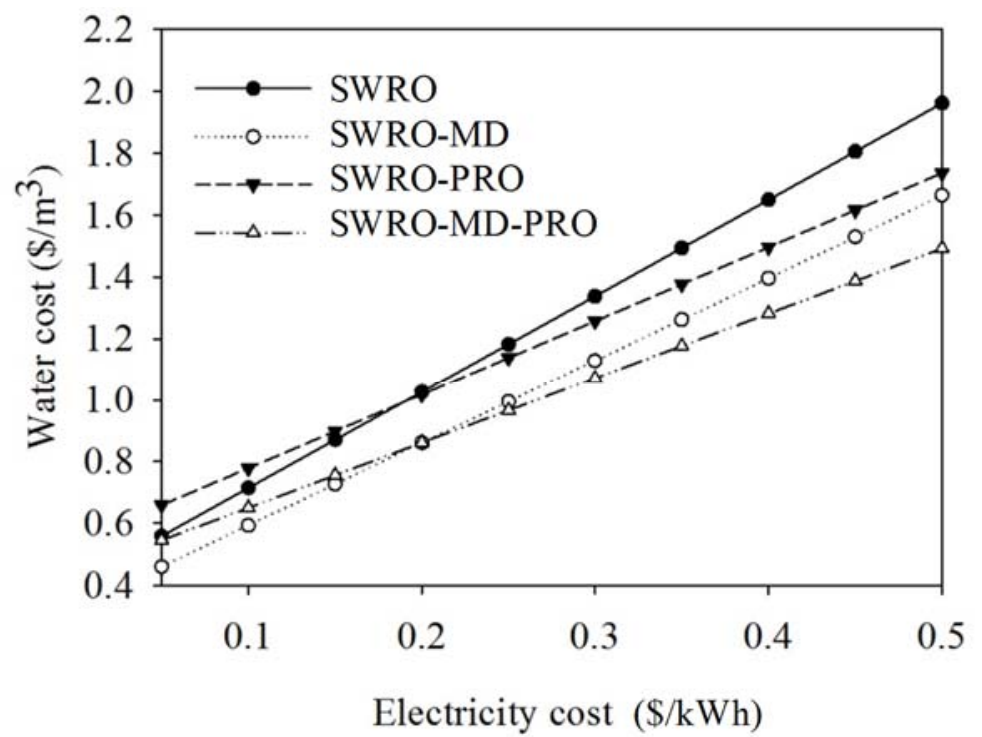

Figure 3. Effect of electricity cost on water cost for RO, RO-MD, RO-PRO, and RO-MD-PRO [77].

\section{Future Prospects}

There are two main obstacles to be overcome for future development of seawater desalination, including high energy consumption and environmental impact of SWRO brine discharge. These two problems cannot be solved separately and more focus should be on the beneficial use of SWRO brine. Reduction of water volume or salt concentration is the approach to mitigate the adverse effect of SWRO brine. At the same time, the salinity gradient energy can be harvested. In this context, many studies have been carried out and the GMVP project is one of these investigations.

However, there are still several technological issues to be considered in the future studies:

- Water recovery from SWRO brine:

o Development of novel membrane materials (for FO and MD) or novel equipment (for evaporation and crystallization)

o Development of hybrid processes that combine evaporation and crystallization toward zero liquid discharge

o Cost-effective resource recovery by crystallization 
o More effective use of renewable energy

o Full-scale implementation (for FO and MD)

- Energy recovery from SWRO brine:

o Development of novel membrane materials (for PRO and RED)

o Development of highly efficient energy recovery device (for PRO) and high performance electrodes (for RED)

o Development of low energy pretreatment techniques

o Optimization of process configuration to maximize net specific energy.

o Improvement of accessibility to impaired water sources.

o Possible hybrid systems of PRO and RED

o Full-scale implementation (for PRO and RED)

- Simultaneous recovery of water and energy from SWRO brine:

o Optimization of water and energy recovery

o Development of new business models

o Full-scale implementation

Although SWRO brine is currently regarded as a hassle, its beneficial use is expected to become a promising concept in near future. This is also a sustainable way to seawater desalination by reducing the environmental risks and water costs at the same time. A systematic approach with a focus on pilot-scale or full-scale implementation will accelerate the realization of this concept.

\section{Acknowledgements}

This research was supported by a grant (code 16IFIP-B065893-05) from Industrial Facilities and Infrastructure Research Program funded by Ministry of Land, Infrastructure and Transport of Korean government.

\section{References}


[1] G.K.C. Ding, S. Ghosh, Sustainable Water Management-A Strategy for Maintaining Future Water Resources A2 - Abraham, Martin A, in: Encyclopedia of Sustainable Technologies, Elsevier, Oxford, 2017, pp. 91-103.

[2] S.M. Olmstead, Climate change adaptation and water resource management: A review of the literature, Energy Economics, 46 (2014) 500-509.

[3] H.M.S. Al-Maamary, H.A. Kazem, M.T. Chaichan, Climate change: The game changer in the Gulf Cooperation Council Region, Renewable and Sustainable Energy Reviews, 76 (2017) 555-576.

[4] V.G. Gude, Desalination and sustainability - An appraisal and current perspective, Water Res, 89 (2016) 87-106.

[5] Global desalination market is worth $\$ 18.37$ billion says Visiongain report, Membrane Technology, 2012 (2012) 16.

[6] Reports highlight current and future trends in the desalination market, Membrane Technology, 2012 (2012) 8-9.

[7] B. Peñate, L. García-Rodríguez, Current trends and future prospects in the design of seawater reverse osmosis desalination technology, Desalination, 284 (2012) 1-8.

[8] Desalination market moving to reverse osmosis, Pump Industry Analyst, 2013 (2013) 3-4.

[9] M.W. Shahzad, M. Burhan, L. Ang, K.C. Ng, Energy-water-environment nexus underpinning future desalination sustainability, Desalination, 413 (2017) 52-64.

[10] A. Alkaisi, R. Mossad, A. Sharifian-Barforoush, A Review of the Water Desalination Systems Integrated with Renewable Energy, Energy Procedia, 110 (2017) 268-274.

[11] S. Miller, H. Shemer, R. Semiat, Energy and environmental issues in desalination, Desalination, 366 (2015) 2-8.

[12] S. Maalouf, D. Rosso, W.W.G. Yeh, Optimal planning and design of seawater RO brine outfalls under environmental uncertainty, Desalination, 333 (2014) 134-145.

[13] N. Ahmad, R.E. Baddour, A review of sources, effects, disposal methods, and regulations of brine into marine environments, Ocean \& Coastal Management, 87 (2014) 1-7.

[14] Modernwater, Brine Concentrator, in, 2016.

[15] N. Akther, A. Sodiq, A. Giwa, S. Daer, H.A. Arafat, S.W. Hasan, Recent advancements in forward osmosis desalination: A review, Chemical Engineering Journal, 281 (2015) 502-522.

[16] C.R. Martinetti, A.E. Childress, T.Y. Cath, High recovery of concentrated RO brines using forward osmosis and membrane distillation, Journal of Membrane Science, 331 (2009) 31-39.

[17] W. Tang, H.Y. Ng, Concentration of brine by forward osmosis: Performance and influence of membrane structure, Desalination, 224 (2008) 143-153.

[18] S. Liyanaarachchi, V. Jegatheesan, S. Muthukumaran, S. Gray, L. Shu, Mass balance for a novel RO/FO hybrid system in seawater desalination, Journal of Membrane Science, 501 (2016) 199-208.

[19] W. Tang, H.Y. Ng, Concentration of brine by forward osmosis: performance and influence of membrane structure, Desalination, 224 (2008) 143-153.

[20] S. Adham, J. Oppenheimer, L. Liu, M. Kumar, Dewatering Reverse Osmosis Concentrate from Water Reuse Applications using Forward Osmosis, in: WateReuse Foundation Research Report, 2007.

[21] Q. Ge, M. Ling, T.-S. Chung, Draw solutions for forward osmosis processes: Developments, challenges, 
and prospects for the future, Journal of Membrane Science, 442 (2013) 225-237.

[22] R.L. McGinnis, N.T. Hancock, M. S.Nowosielski-Slepowron, G.D. McGurgan, Pilot demonstration of the NH3/CO2 forward osmosis desalination process on high salinity brines, Desalination, 312 (2013) 67-74.

[23] B.D. Coday, P. Xu, E.G. Beaudry, J. Herron, K. Lampi, N.T. Hancock, T.Y. Cath, The sweet spot of forward osmosis: Treatment of produced water, drilling wastewater, and other complex and difficult liquid streams, Desalination, 333 (2014) 23-35.

[24] D.L. Shaffer, J.R. Werber, H. Jaramillo, S. Lin, M. Elimelech, Forward osmosis: Where are we now?, Desalination, 356 (2015) 271-284.

[25] T.V. Bartholomew, L. Mey, J.T. Arena, N.S. Siefert, M.S. Mauter, Osmotically assisted reverse osmosis for high salinity brine treatment, Desalination, 421 (2017) 3-11.

[26] J. Morillo, J. Usero, D. Rosado, H. El Bakouri, A. Riaza, F.-J. Bernaola, Comparative study of brine management technologies for desalination plants, Desalination, 336 (2014) 32-49.

[27] L. Philip, K.S. Reddy, B. Kumar, S.M. Bhallamudi, A. Kannan, Performance evaluation of a solar and wind aided cross-flow evaporator for RO reject management, Desalination, 317 (2013) 1-10.

[28] A. Giwa, V. Dufour, F. Al Marzooqi, M. Al Kaabi, S.W. Hasan, Brine management methods: Recent innovations and current status, Desalination, 407 (2017) 1-23.

[29] M. Ahmed, W.H. Shayya, D. Hoey, A. Mahendran, R. Morris, J. Al-Handaly, Use of evaporation pods for brine disposal in desalination plants, Desalination, 130 (2000) 155-168.

[30] J. Gilron, Y. Folkman, R. Savliev, W. Waisman, O. Keden, WAIV - wind aided intensified evaporation for reduction of desalination brine volume, Desalination, 158 (200) 205-214.

[31] S.E. Aly, Combined RO/VC Desalination System, Desalination, 58 (1986) 85-97.

[32] A. Cipollina, G. Micale, L. Rizzuti, A brine evaporative cooler/concentrator for autonomous thermal desalination units, Desalination and Water Treatment, 31 (2011) 269-278.

[33] J.P. Mericq, S. Laborie, C. Cabassud, Vacuum membrane distillation of seawater reverse osmosis brines, Water Res, 44 (2010) 5260-5273.

[34] Y. Choi, G. Naidu, S. Jeong, S. Vigneswaran, S. Lee, R. Wang, A.G. Fane, Experimental comparison of submerged membrane distillation configurations for concentrated brine treatment, Desalination, 420 (2017) 54-62.

[35] Z. Yan, H. Yang, F. Qu, H. Yu, H. Liang, G. Li, J. Ma, Reverse osmosis brine treatment using direct contact membrane distillation: Effects of feed temperature and velocity, Desalination, (2017).

[36] J.A. Sanmartino, M. Khayet, M.C. García-Payo, H. El-Bakouri, A. Riaza, Treatment of reverse osmosis brine by direct contact membrane distillation: Chemical pretreatment approach, Desalination, 420 (2017) 79-90.

[37] L. Mariah, C.A. Buckley, C.J. Brouckaert, E. Curcio, E. Drioli, D. Jaganyi, D. Ramjugernath, Membrane distillation of concentrated brines e role of water activities in the evaluation of driving force, Journal of Membrane Science, 280 (2006) 937-947.

[38] B.B. Ashoor, S. Mansour, A. Giwa, V. Dufour, S.W. Hasan, Principles and applications of direct contact membrane distillation (DCMD): A comprehensive review, Desalination, 398 (2016) 222-246.

[39] A. Alkhudhiri, N. Darwish, N. Hilal, Membrane distillation: A comprehensive review, Desalination, 287 (2012) 2-18. 
[40] E. Drioli, A. Ali, F. Macedonio, Membrane distillation: Recent developments and perspectives, Desalination, 356 (2015) 56-84.

[41] M.A.E.-R. Abu-Zeid, Y. Zhang, H. Dong, L. Zhang, H.-L. Chen, L. Hou, A comprehensive review of vacuum membrane distillation technique, Desalination, 356 (2015) 1-14.

[42] K. Rahaoui, L.C. Ding, L.P. Tan, W. Mediouri, F. Mahmoudi, K. Nakoa, A. Akbarzadeh, Sustainable Membrane Distillation Coupled with Solar Pond, Energy Procedia, 110 (2017) 414-419.

[43] D. González, J. Amigo, F. Suárez, Membrane distillation: Perspectives for sustainable and improved desalination, Renewable and Sustainable Energy Reviews, 80 (2017) 238-259.

[44] Y. Zhang, Y. Peng, S. Ji, Z. Li, P. Chen, Review of thermal efficiency and heat recycling in membrane distillation processes, Desalination, 367 (2015) 223-239.

[45] Q.-M. Nguyen, S. Jeong, S. Lee, Characteristics of membrane foulants at different degrees of SWRO brine concentration by membrane distillation, Desalination, 409 (2017) 7-20.

[46] J. Ge, Y. Peng, Z. Li, P. Chen, S. Wang, Membrane fouling and wetting in a DCMD process for RO brine concentration, Desalination, 344 (2014) 97-107.

[47] D.G. Randall, J. Nathoo, A succinct review of the treatment of Reverse Osmosis brines using Freeze Crystallization, Journal of Water Process Engineering, 8 (2015) 186-194.

[48] F. Farahbod, D. Mowla, M.R. Jafari Nasr, M. Soltanieh, Experimental study of forced circulation evaporator in zero discharge desalination process, Desalination, 285 (2012) 352-358.

[49] J.-H. Tsai, F. Macedonio, E. Drioli, L. Giorno, C.-Y. Chou, F.-C. Hu, C.-L. Li, C.-J. Chuang, K.-L. Tung, Membrane-based zero liquid discharge: Myth or reality?, Journal of the Taiwan Institute of Chemical Engineers, (2017).

[50] F. Macedonio, C.A. Quist-Jensen, O. Al-Harbi, H. Alromaih, S.A. Al-Jlil, F. Al Shabouna, E. Drioli, Thermodynamic modeling of brine and its use in membrane crystallizer, Desalination, 323 (2013) 83-92.

[51] X. Ji, E. Curcio, S. Al Obaidani, G. Di Profio, E. Fontananova, E. Drioli, Membrane distillationcrystallization of seawater reverse osmosis brines, Separation and Purification Technology, 71 (2010) 76-82.

[52] E. Drioli, G. Di Profio, E. Curcio, Progress in membrane crystallization, Current Opinion in Chemical Engineering, 1 (2012) 178-182.

[53] M. Turek, K. Mitko, K. Piotrowski, P. Dydo, E. Laskowska, A. Jakóbik-Kolon, Prospects for high water recovery membrane desalination, Desalination, 401 (2017) 180-189.

[54] Y. Shin, J. Sohn, Mechanisms for scale formation in simultaneous membrane distillation crystallization: Effect of flow rate, Journal of Industrial and Engineering Chemistry, 35 (2016) 318-324.

[55] O. Schaetzle, C.J.N. Buisman, Salinity Gradient Energy: Current State and New Trends, Engineering, 1 (2015) 164-166.

[56] A. Altaee, A. Sharif, Pressure retarded osmosis: advancement in the process applications for power generation and desalination, Desalination, 356 (2015) 31-46.

[57] G. O'Toole, L. Jones, C. Coutinho, C. Hayes, M. Napoles, A. Achilli, River-to-sea pressure retarded osmosis: Resource utilization in a full-scale facility, Desalination, 389 (2016) 39-51.

[58] W. He, Y. Wang, M.H. Shaheed, Energy and thermodynamic analysis of power generation using a natural salinity gradient based pressure retarded osmosis process, Desalination, 350 (2014) 86-94.

[59] S. Sarp, Z. Li, J. Saththasivam, Pressure Retarded Osmosis (PRO): Past experiences, current 
developments, and future prospects, Desalination, 389 (2016) 2-14.

[60] D.A. Vermaas, M. Saakes, K. Nijmeijer, Power generation using profiled membranes in reverse electrodialysis, J. Membrane. Sci., 385 (2011) 234-242.

[61] S. S, S. S, Reverse Osmosis-Pressure Retarded Osmosis hybrid system: Modelling, simulation and optimization, Desalination, 389 (2016) 78-97.

[62] C.F. Wan, T.-S. Chung, Energy recovery by pressure retarded osmosis (PRO) in SWRO-PRO integrated processes, Applied Energy, 162 (2016) 687-698.

[63] A. Kumano, K. Marui, Y. Terashima, Hollow fiber type PRO module and its characteristics, Desalination, 389 (2016) 149-154.

[64] J. Kim, M.J. Park, M. Park, H.K. Shon, S.-H. Kim, J.H. Kim, Influence of colloidal fouling on pressure retarded osmosis, Desalination, 389 (2016) 207-214.

[65] Q. She, R. Wang, A.G. Fane, C.Y. Tang, Membrane fouling in osmotically driven membrane processes: A review, Journal of Membrane Science, 499 (2016) 201-233.

[66] Y. Choi, S. Vigneswaran, S. Lee, Evaluation of fouling potential and power density in pressure retarded osmosis (PRO) by fouling index, Desalination, 389 (2016) 215-223.

[67] H.W. Chung, K.G. Nayar, J. Swaminathan, K.M. Chehayeb, J.H. Lienhard V, Thermodynamic analysis of brine management methods: Zero-discharge desalination and salinity-gradient power production, Desalination, 404 (2017) 291-303.

[68] M. Turek, B. Bandura, Renewable energy by reverse electrodialysis, Desalination, 205 (2007) 67-74.

[69] D.A. Vermaas, E. Guler, M. Saakes, K. Nijmeijer, Theoretical power density from salinity gradients using reverse electrodialysis, Energy Procedia, 20 (2012) 170-184.

[70] J. Koo, S. Lee, J.-S. Choi, T.-M. Hwang, Theoretical analysis of different membrane distillation modules, Desalination and Water Treatment, 54 (2015) 862-870.

[71] Y. Park, Y. Shin, J. Choi, Y. Choi, S. Lee, Analysis of flux and energy efficiency for hollow fiber module in direct contact membrane distillation process, Desalination and Water Treatment, 77 (2017) 30-38.

[72] H. Cho, Y.-J. Choi, S. Lee, J. Koo, T. Huang, Comparison of hollow fiber membranes in direct contact and air gap membrane distillation (MD), Desalination and Water Treatment, 57 (2016) 10012-10019.

[73] Y. Shin, J. Choi, T. Lee, J. Sohn, S. Lee, Optimization of dewetting conditions for hollow fiber membranes in vacuum membrane distillation, Desalination and Water Treatment, 57 (2016) 7582-7592.

[74] Y. Shin, J. Choi, Y. Park, Y. Choi, S. Lee, Influence of Operation Conditions on the Performance of Pilotscale Vacuum Membrane Distillation (VMD), Desalination and Water Treatment, In press (2017).

[75] Y.J. E.J. Jeon, J.H.L. Sim, Development of thin-film composite PRO membranes with high power density, Desalination and Water Treatment, 57 (2016) 10093-10100.

[76] K. Chung, I.-H. Yeo, W. Lee, Y.K. Oh, D. Kim, Y.-G. Park, Investigation into design parameters in seawater reverse osmosis (SWRO) and pressure retarded osmosis (PRO) hybrid desalination process: a semi-pilot scale study, Desalination and Water Treatment, 57 (2016) 24636-24644.

[77] Y. Choi, S.-H. Kim, S. Lee, Comparison of performance and economics of reverse osmosis, membrane distillation, and pressure retarded osmosis hybrid systems, Desalination and Water Treatment, 77 (2017) 19-29. 